\title{
Transgenic rescue of insulin receptor-deficient mice
}

\author{
Haruka Okamoto,, ${ }^{1,2}$ Jun Nakae, ${ }^{1}$ Tadahiro Kitamura, ${ }^{1}$ Byung-Chul Park, \\ Ioannis Dragatsis, ${ }^{3}$ and Domenico Accili1,2
}

\begin{abstract}
1Department of Medicine and 2Institute of Human Nutrition, College of Physicians and Surgeons, Columbia University, New York, New York, USA.
${ }^{3}$ Department of Physiology, University of Tennessee, Memphis, Tennessee, USA.
\end{abstract}

\begin{abstract}
The role of different tissues in insulin action and their contribution to the pathogenesis of diabetes remain unclear. To examine this question, we have used genetic reconstitution experiments in mice. Genetic ablation of insulin receptors causes early postnatal death from diabetic ketoacidosis. We show that combined restoration of insulin receptor function in brain, liver, and pancreatic $\beta$ cells rescues insulin receptor knockout mice from neonatal death, prevents diabetes in a majority of animals, and normalizes adipose tissue content, lifespan, and reproductive function. In contrast, mice with insulin receptor expression limited to brain or liver and pancreatic $\beta$ cells are rescued from neonatal death, but develop lipoatrophic diabetes and die prematurely. These data indicate, surprisingly, that insulin receptor signaling in noncanonical insulin target tissues is sufficient to maintain fuel homeostasis and prevent diabetes.
\end{abstract}

\section{Introduction}

The mechanism of insulin action is a central question in biology, with important ramifications for human disease (1). Impaired insulin action, or insulin resistance, is commonly observed in type 2 diabetes and predisposes to obesity, arteriosclerosis, and cardiovascular diseases (2). It remains unclear whether insulin resistance is initially restricted to selected tissues and cell types or whether it represents a systemic abnormality of insulin action. To examine the contribution of individual tissues and cell types to the pathogenesis of insulin resistance, we and others have generated constitutive and conditional null alleles of insulin receptor (Insr) to inactivate its function in mice (3). Complete Insr ablation results in early postnatal death from diabetes $(4,5)$. In contrast, conditional Ins r ablation in specific tissues results in mild but complex metabolic abnormalities (6-9). The latter experiments support two conclusions: (a) that insulin resistance in any given tissue can be compensated for through substrate redistribution to other organs $(7,10)$, and (b) that insulin has direct actions on tissues that have generally not been considered insulin sensitive, such as pancreatic $\beta$ cells and brain $(7,8,11)$. These observations complement work showing that combined functional Ins $r$ knockout in muscle and adipose tissue does not lead to diabetes (12).

To study the role of noncanonical insulin target tissues in the pathogenesis of type 2 diabetes and to circumvent the problem of compensation by other tissues, we used a genetic reconstitution approach. We asked whether re-expression of Insr in selected tissues of Insr-deficient mice would confer protection from the metabolic abnormalities that cause diabetes. Our data lend support to the surprising conclusion that insulin action in tissues that are not dependent on insulin for glucose uptake (liver, brain, and pancreatic $\beta$ cells) is sufficient to restore metabolic homeostasis and prevent diabetes.

Nonstandard abbreviations used: -actin ( ac); insulin receptor (Insr); internal ribosome entry site (IRES); rat insulin II promoter (Rip); transthyretin (Ttr). Conflict of interest: The authors have declared that no conflict of interest exists.

Citation for this article: J. Clin. Invest. 114:214-223 (2004).

doi:10.1172/JCI200421645.

\section{Results}

In attempting to rescue Insr-deficient mice, we had to consider the peculiar metabolism of the newborn mouse, which is dependent mainly on the liver's ability to generate ketones as an energy source for the developing brain (13). Although the early postnatal period is characterized by a fall in insulin levels (13), the establishment of insulin-dependent fuel-sensing mechanisms is required to restrain hepatic gluconeogenesis and promote glycogen storage. Indeed, liver failure appears to be the leading cause of death of Insr knockouts $(4,5)$. Therefore, we considered reconstitution of Insr expression in liver the sine qua non for further metabolic compensation.

Generation of transthyretin-Insr lines. We generated three lines of transgenic mice expressing human INSR cDNA from the transthyretin (Ttr) promoter (referred to here as L1, L2, and L3). The Ttr promoter has been shown to drive transgene expression in liver and choroid plexus. Moreover, it shows copy number- and integration site-dependent expression in pancreatic $\beta$ cells and brain (14-16). Southern blot analysis indicated that transgene copy number varied between 20 (L1) and 1 (L3) (data not shown). We used Northern blotting to confirm transgene expression in liver. We detected the highest levels of transgene-encoded mRNA (INSR ${ }^{\mathrm{tg}}$ ) in L1 liver. The levels in L2 and L3 livers were approximately $37 \%$ and $29 \%$ of those in L1 liver (Figure 1A). RT-PCR revealed that, in addition to liver, pancreatic islets expressed the transgene in all three lines (Figure 1B). Based on previous work with the Ttr promoter in transgenic mice, this expression is likely to arise from pancreatic $\beta$ cells $(14,17)$. To determine whether the transgene was also expressed in brain, we dissected different brain parts from the three lines and performed real-time RT-PCR using a primer set that specifically amplifies human INSR. We detected expression of the transgene in all brain parts derived from L1 mice but in none of those derived from L2 and L3 mice (Figure 1C). Widespread brain expression from the Ttr promoter has also been reported $(18,19)$.

Characterization of Ttr-Insr mice. We intercrossed the three lines with Insr ${ }^{+/-}$mice to generate Ttr transgenic mice lacking endogenous Insr (Ttr-Inst/-). Unlike Inst ${ }^{-/-}$mice, which died within days 
A Liver Northern blot

WT L1 L2 L3

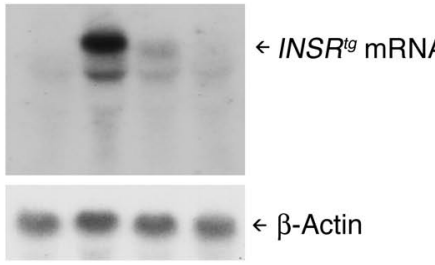

B Islet RT-PCR

WT L1 L2 L3 WT L1 L2 L3

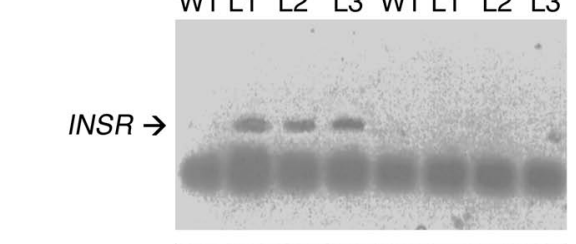

Glucagon $\rightarrow$

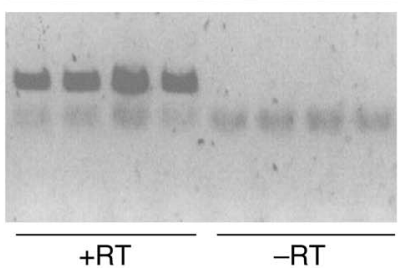

C Brain RT-PCR

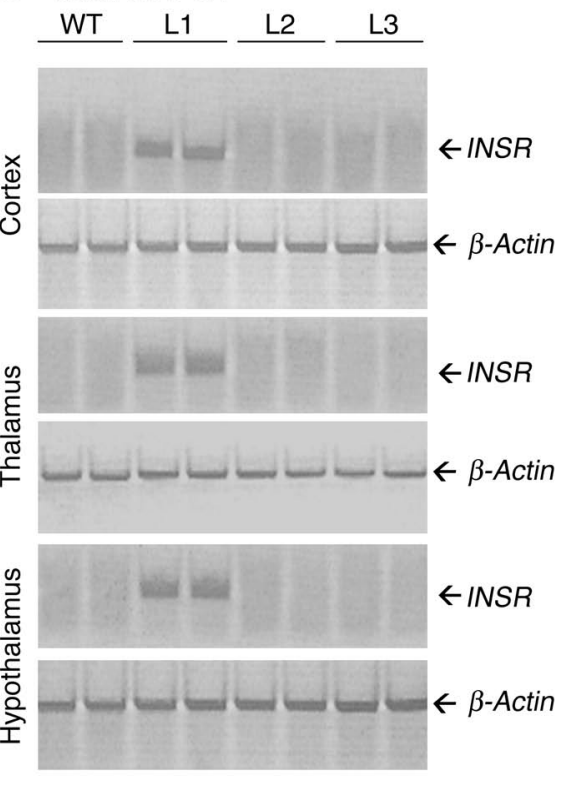

\section{Figure 1}

Generation of Ttr-Insr transgenic mice. (A) Northern blot analysis of liver mRNA. We hybridized poly $(A)+$ RNA from three founders with the same cDNA probe used in $\mathbf{A}$ for Northern analysis. This probe does not detect endogenous murine transcripts. (B) RT-PCR of mRNA isolated from pancreatic islets. The upper panel shows amplification of the transgenic INSR, and the lower panel shows amplification of glucagon as a control. $+\mathrm{RT}$, with reverse transcriptase; $-\mathrm{RT}$, without reverse transcriptase. (C) RT-PCR of brain mRNA. The primer sets used to amplify the transgenic INSR and $\beta a c$ control are available from the authors. The upper panel of each pair shows duplicate samples of INSR amplification, whereas the lower panel of each pair shows $\beta$ ac control. of birth, Ttr-Insr ${ }^{-1}$ mice from all three lines survived to adulthood. All three lines showed evidence of growth retardation at 1 month. The body weights of male L1 (Figure 2A) and L2 (Figure 2B) mice were about $80 \%$ those of control littermates, whereas those of male
L3 mice (Figure 2C) were about 60\% those of control littermates. L1 mice exhibited limited post-weaning "catch-up" growth, whereas L2 and L3 mice remained growth retarded throughout life. We obtained similar data in female mice (not shown). Necroscopic
A
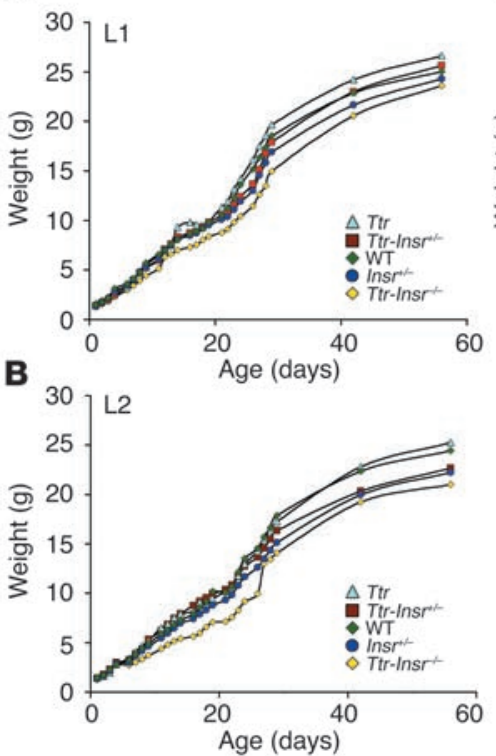

C

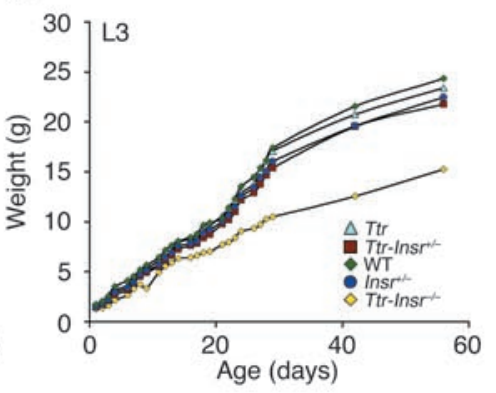

D

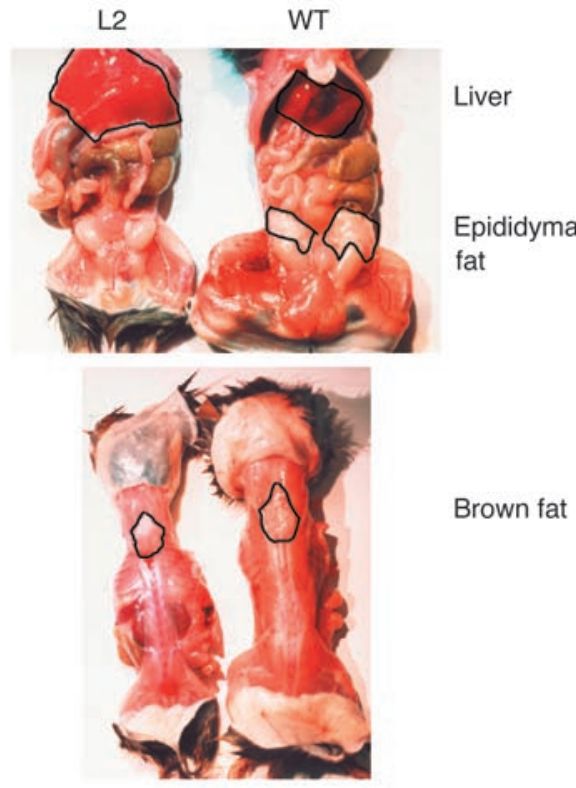

\section{Figure 2}

Analysis of growth retardation. (A-C) Growth curves of transgenic lines. For each line, we present mean body weights. The number of animals studied is indicated in parenthesis for each line: WT ( $n=7$ for L1, 10 for L2, and 7 for L3), Ttr $(n=2,4$, and 7, respectively), Ttr-Insr+/- $(n=15$,

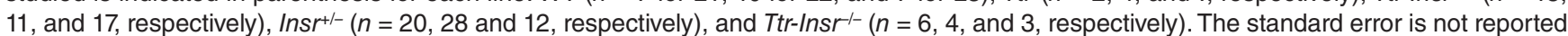

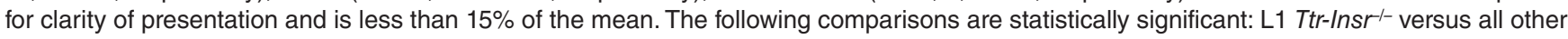
L1 genotypes ( $P<0.05$ by ANOVA), L2 Ttr-Ins $r^{-1}$ versus all other genotypes $\left(P<0.05\right.$ by ANOVA), and L3 Ttr-Inst ${ }^{-1}$ versus all other genotypes $(P<0.05$ by ANOVA). (D) Necroscopic analysis of representative 3 -week-old L2 transgenic and WT mice demonstrates lack of white adipose tissue (upper panel) but preservation of interscapular brown adipose tissue (lower panel) in L2 mice. We observed a similar phenotype in L3 mice. 
A

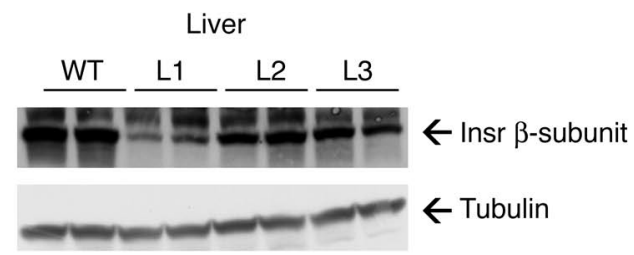

C

Brain

L1 L2 L3 WT L1 L2 L3 WT

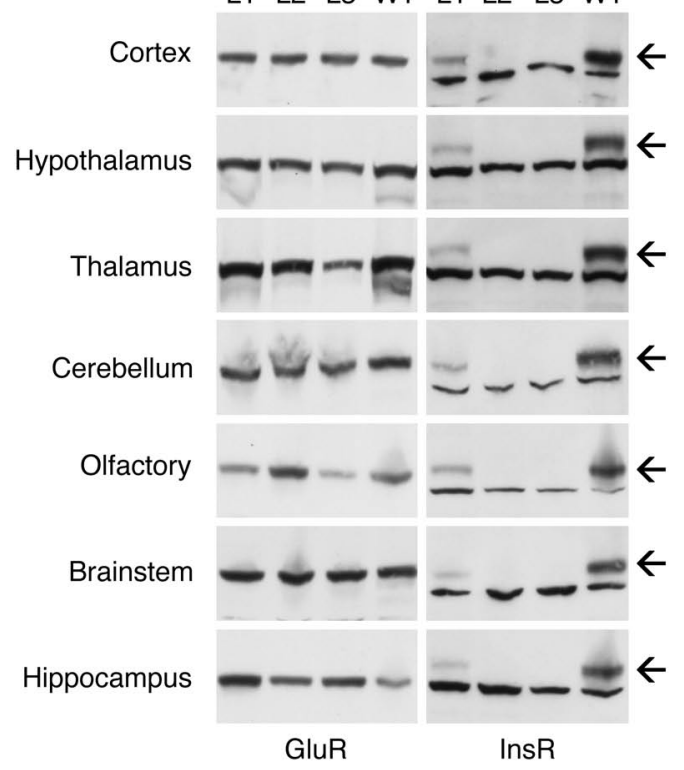

B Islets

WT L1 L2 L3

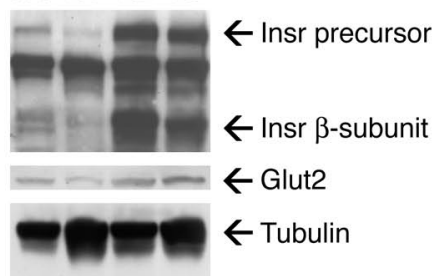

D Other tissues
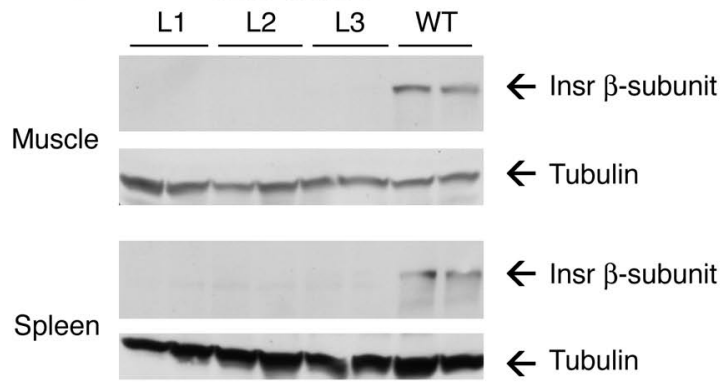

Heart

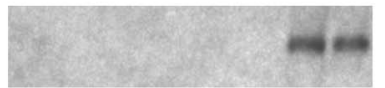

$\leftarrow \operatorname{lnsr} \beta$-subunit

Adipose

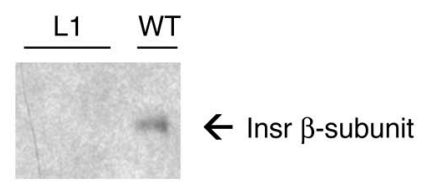

\section{Figure 3}

Immunoblot analysis of Insr expression in different tissues of the transgenic knockouts. (A) Liver. The upper panel represents an autoradiogram showing immunoreactivity with anti-Insr antiserum; the lower panel shows an immunoblot with anti-tubulin antiserum to confirm equal loading of all lanes. We used 3- to 4-month-old animals for these determinations. (B) Islets. For these experiments, we partially purified islets by Ficoll density gradient centrifugation. Please note the prominent band corresponding to the receptor precursor (Insr precursor). To normalize for $\beta$-cell content, we used the $\beta$ cell-specific marker Glut2 (middle panel). We used tubulin to normalize for total protein content (bottom panel). We used 2-month-old animals for these experiments. (C) Widespread transgene expression in brains of L1 Ttr-Insr mice. We obtained specimens from different brain sections and analyzed them by immunoblot. On the left, we present a control obtained with anti-glutamate receptor antiserum (GluR) to normalize for gel loading. On the right, we show immunoblots with anti-Insr antiserum. Arrows indicate the position of the Insr $\beta$-subunit. We used 3- to 4-month-old animals for these determinations. (D) Lack of Insr expression in muscle, heart, spleen, and adipose tissue. We show representative blots of 3- to 4-month-old mice. We obtained similar results with specimens from mice of different ages. We could not obtain adipose tissue from L2 and L3 mice because they are lipoatrophic.

analyses indicated that L2 and L3 mice lacked white adipose tissue while retaining interscapular brown adipose tissue. In addition, both L2 and L3 mice showed considerable hepatomegaly and fatty liver degeneration (Figure 2D), as expected from their lipoatrophic state. In contrast, L1 mice had normal adipose tissue content and distribution (not shown).

We assessed Insr expression by immunoblot and insulin-binding assay. In liver, immunoreactive Insr levels were $57 \%$ of WT in L1 mice and $75 \%$ of WT in L2 and L3 mice (Figure 3A). Interestingly, L1 mice expressed lower protein levels, despite having higher levels of mRNA (compare Figure 1A with Figure 3A). This discrepancy is likely to arise from integration site effects. In islets, L1 mice expressed Insr at levels about 50\% of WT, whereas L2 and L3 mice showed levels about fivefold higher than WT. As seen previously with other receptors of the Insr family expressed in pancreatic $\beta$ cells $(20,21)$, the band corresponding to the $190-\mathrm{kDa}$ receptor precursor was more prominent in pancreatic $\beta$ cells than in other cell types (Figure 3B). Consistent with the results of real-time RTPCR (Figure 1C), we detected Insr immunoreactivity in all brain parts from L1 Ttr-Insr ${ }^{-}$- mice but in none of those from L2 and L3 mice. Expression levels were uniformly lower than in control mice, reaching about $36 \%$ of WT in hypothalamus, $26 \%$ in thalamus, $51 \%$ in cortex, $63 \%$ in olfactory lobe, $53 \%$ in cerebellum, $59 \%$ in hippocampus, and 39\% in brainstem (Figure 3C). We did not detect Insr immunoreactivity in muscle, heart, or spleen from any TtrInst/- line, nor in the epididymal fat pads of L1 mice (Figure 3D). Analysis of additional tissues (lung, kidney, intestine, bone, and peripheral blood cells) also failed to reveal Insr immunoreactivity (not shown). Insulin-binding assays also failed to detect insulinbinding activity in any of these tissues. 

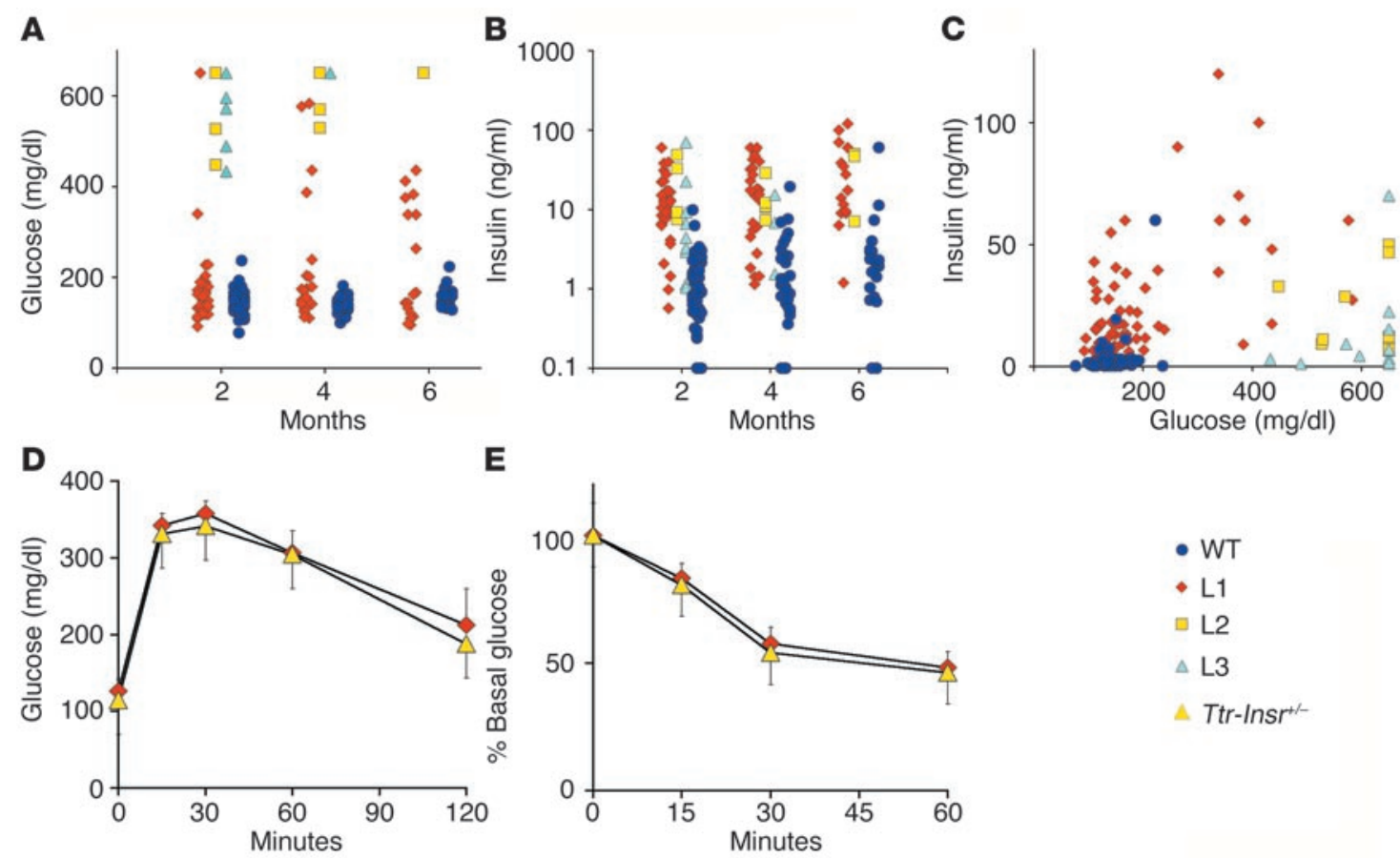

E
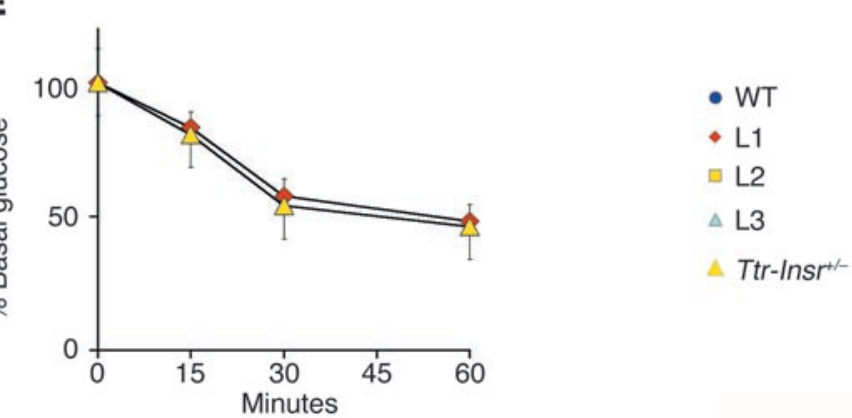

Figure 4

Metabolic tests. (A and B) Glucose and insulin values in individual Ttr-Ins/ ${ }^{-1}$ and WT mice at various ages. (C) Correlation of insulin (vertical axis) and glucose (horizontal axis) values in 2- to 6-month-old mice. (D and E) Intraperitoneal glucose and insulin tolerance tests in 4-month-old L1 Ttr-Insr ${ }^{+-}$and Ttr-Insr ${ }^{-1-}$ transgenic mice ( $n=6$ for each genotype). Animals were fasted for 4 and 12 hours prior to the insulin and glucose tolerance tests.

Metabolic profile of Ttr-Insr mice. To determine the physiological consequences of limited restoration of Insr expression, we measured glucose and insulin levels in mice of various ages. At 2 months of age, $90 \%$ of L1 mice showed normal glucose levels and $10 \%$ showed glucose levels in the diabetic range (defined as mean $+2 \mathrm{SD})$. By the age of 6 months, the percentage of $\mathrm{L} 1$ mice that were diabetic rose to $35 \%$ (6 of 17), but they all had normal lifespans. In contrast, all L2 and L3 Ttr-Inst-1- mice developed diabetes by 2 months and died between 3 weeks and 8 months of age. Indeed, in L3 mice we observed hyperglycemia as early as 4 weeks of age, and $90 \%$ of mice died by 2 months of age (Figure 4A and Table 1). The variability of the phenotype in L2 and L3 mice, which have similar expression levels and tissue patterns of the transgene, is likely to arise from the contribution of modifier genes on the outbred $\mathrm{C} 57 \mathrm{BL} / 6 \times$ FVB $\times 129 /$ Sv genetic background. All lines of Ttr-Insr- ${ }^{-1}$ mice showed substantial increases in circulating insulin levels (Figure 4B and Table 1). As in other models of insulin resistance (22), we observed a "bell-shaped correlation" between glucose and insulin values (Figure 4C). However, whereas the majority of $\mathrm{L} 1$ mice displayed compensatory hyperinsulinemia with normal glucose levels, L2 and L3 mice with similar insulin values had considerably higher glucose levels, suggestive of progressive exhaustion of the pancre- atic $\beta$-cell compensatory capacity. To detect metabolic abnormalities that do not result in diabetes, we subjected nondiabetic L1 mice to glucose and insulin tolerance tests. Both tests failed to reveal abnormalities of glucose disposal (Figure 4, D and E). We obtained similar data in 8-month-old mice. These data indicate that the majority of $\mathrm{L} 1$ mice are protected from diabetes throughout life. Moreover, measurements of circulating free fatty acids, total cholesterol, and triglycerides failed to reveal differences between L1 and control mice (data not shown). Food intake and body composition were also normal, and we detected a $10 \%$ increase in resting energy expenditure in L1 compared with control mice (H. Okamoto, S. Obici, D. Accili, and L. Rossetti, unpublished observations). Nevertheless, some L1 mice develop diabetes, suggesting that the genetic background
Table 1

Metabolic features of Ttr-Insr transgenic knockout mice

\begin{tabular}{|c|c|c|c|c|}
\hline Genotype & WT & L1 Ttr-Insr ${ }^{-}$ & L2 Ttr-Insr ${ }^{-}-$ & L3 Ttr-Insr ${ }^{--}$ \\
\hline 2-mo glucose & $141 \pm 3(n=54)$ & $172 \pm 17(n=34)$ & $569 \pm 50^{A}(n=4)$ & $586 \pm 30^{\mathrm{B}}(n=9)$ \\
\hline 4-mo glucose & $138 \pm 3(n=32)$ & $214 \pm 27(n=23)$ & $>600^{\mathrm{B}}(n=5)$ & $>600^{\mathrm{B}}(n=3)$ \\
\hline 6-mo glucose & $153 \pm 5(n=21)$ & $197 \pm 15(n=17)$ & $>600^{B}(n=3)$ & $\mathrm{N} / \mathrm{A}$ \\
\hline 2-mo insulin & $1.5 \pm 0.2(n=53)$ & $14.8 \pm 2.1^{\mathrm{B}}(n=34)$ & $24.5 \pm 9.9(n=4)$ & $6.4 \pm 2.5(n=9)$ \\
\hline 4-mo insulin & $2.4 \pm 0.6(n=32)$ & $21.8 \pm 3.7^{\mathrm{B}}(n=26)$ & $13.9 \pm 3.7(n=5)$ & $8.4 \pm 6.9(n=3)$ \\
\hline 6-mo insulin & $5.2 \pm 2.7(n=22)$ & $38.7 \pm 9.5^{\mathrm{A}}(n=15)$ & $28.5 \pm 13.8(n=3)$ & $\mathrm{N} / \mathrm{A}$ \\
\hline Hepatic glycogen & $84.1(n=2)$ & $81.9(n=2)$ & $62.5(n=2)$ & $42.4(n=2)$ \\
\hline
\end{tabular}

We express glucose as $\mathrm{mg} / \mathrm{dl}$, insulin as $\mathrm{ng} / \mathrm{ml}$, and glycogen as $\mathrm{mg} / \mathrm{g}$ protein. Statistically significant differences are indicated as follows: ${ }^{A} P<0.005 ;{ }^{B} P<0.001$. N/A, not applicable. 2-mo, 2-month-old mouse. 
A $\quad W T$
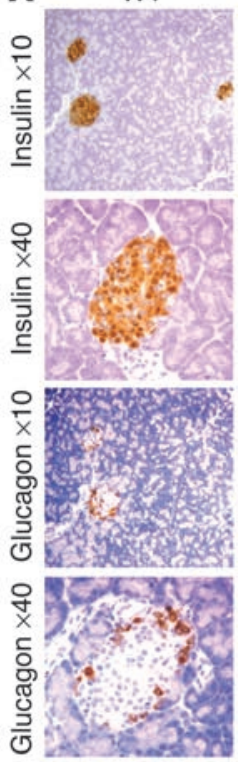

C
L1
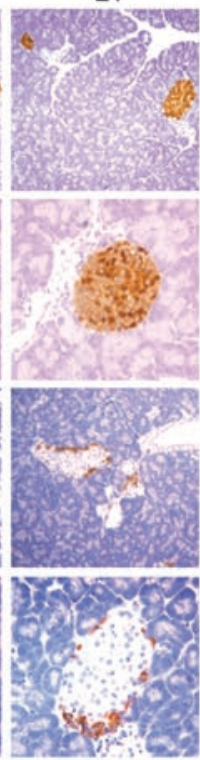

L1

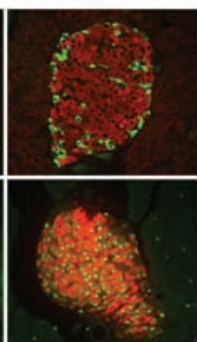

L2
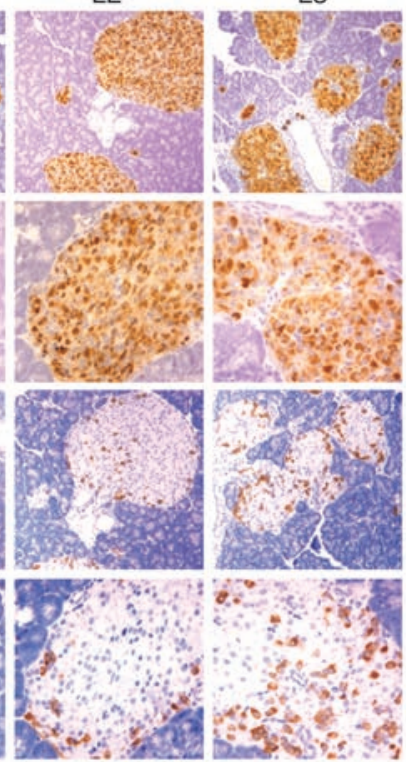

L2

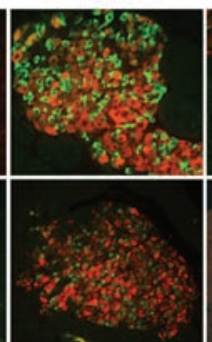

L3
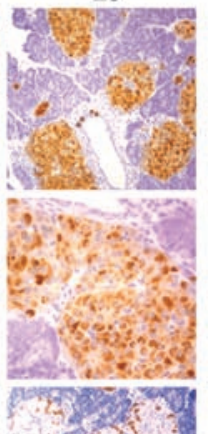

B

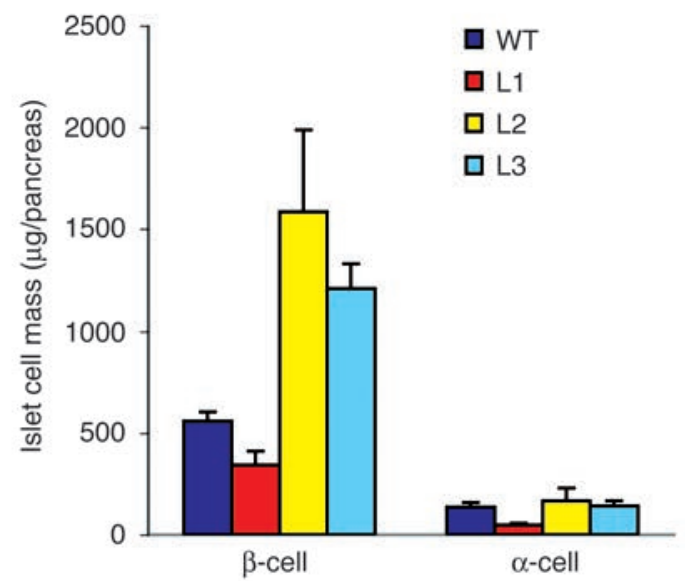

\section{Figure 5}

Pancreatic islet morphology. (A) We show the typical appearance of islets in 1-month-old mice from each of the Ttr-Insr lines. The upper two rows show immunostaining with anti-insulin and the lower two rows, with anti-glucagon antiserum. (B) Morphometric evaluation of $\beta$-cell mass. We determined $\alpha$ - and $\beta$-cell area by manually tracing immunoreactive cells in nonoverlapping fields from sections obtained at least $80 \mu \mathrm{m}$ apart. We analyzed three sections per mouse and four mice per genotype. Area values were multiplied by total pancreas weight to obtain islet cell mass. (C) Altered islet size and morphology in 4-month-old L2 and L3 mice. The upper panels show double immunostaining with anti-insulin (red) and anti-glucagon (green) antisera. The lower panels show double immunohistochemistry with anti-insulin (red) and anti-Pdx1 (green) antisera.

modifies the transgene effect, as we have shown previously for Insr mutations (23). To rule out the possibility that the main effect of the Ttr-driven transgene is due to genetic background, we intercrossed $\mathrm{L} 1$ mice with $\mathrm{L} 2$ and $\mathrm{L} 3$ mice. In the resulting $\mathrm{F}_{1}$ generation, single hemizygosity for L1 and compound hemizygosity for the L1/L2 or L1/L3 combination of transgenic alleles consistently conferred protection from diabetes and premature death, whereas all single-hemizygous mice carrying the L2 and L3 transgenes, alone or in combination, died of diabetes. These data indicate that the protective effect is tightly associated with the $\mathrm{L} 1$ transgene and not with modifier genes.

We next assessed gene expression in livers of 4-week-old Ttr-Insr ${ }^{-}$mice using real-time RT-PCR. We detected an increase of about $80 \%$ in glucose-6-phosphatase (G6pc) exclusively in L2 mice, whereas phosphoenolpyruvate carboxykinase (Pck1) levels were unperturbed. In L2 and L3 mice we also detected an increase of about twofold in insulin-like growth factor-binding protein 1 (Ifgbp1) and a decrease of $60-80 \%$ in glycogen synthase (Gys1) levels. As expected, given the reduced Gys 1 expression, we detected a decrease in liver glycogen content in L2 and L3 mice compared with control mice, whereas glycogen content in L1 mice was normal (Table 1). These results are consistent with hepatic insulin resistance in L2 and L3 mice, although some changes, such as the decrease in glycogen levels,

\section{Table 2}

Synopsis of breeding experiments

\begin{tabular}{|c|c|c|c|c|}
\hline \multicolumn{2}{|c|}{ Breeding pair (genotype) } & $n$ & Litters & Litter size \\
\hline M & $F$ & & & \\
\hline L1 Ttr-Insr-1- & Insr'+- & 4 & 4 & $7 \pm 1.5$ \\
\hline L2 Ttr-Insr ${ }^{-1}$ & $\operatorname{lnsr}^{+/-}$ & 4 & 4 & $7 \pm 1.4$ \\
\hline L3 Ttr-Insr-1- & $\operatorname{lnsr}^{+/-}$ & 2 & 2 & $9 \pm 1$ \\
\hline $\mathrm{InSr}^{+-}$ & L1 Ttr-Insr-1- & 4 & 4 & $9 \pm 1.4$ \\
\hline Inst+/- & L2 Ttr-Insr ${ }^{-1}$ & 4 & 0 & $\mathrm{~N} / \mathrm{A}$ \\
\hline Insrt/- & L3 Ttr-Insr-1- & 4 & 0 & $\mathrm{~N} / \mathrm{A}$ \\
\hline L1 Ttr-Insr-1- & L1 Ttr-Insr-1- & 4 & 4 & $9 \pm 0.7$ \\
\hline
\end{tabular}

For each mating, we report the number of pairs $(n)$, the number of litters produced (Litters) within a month, and the mean number of pups $( \pm$ SEM) in each litter (Litter size). M, male; $F$, female. 
A

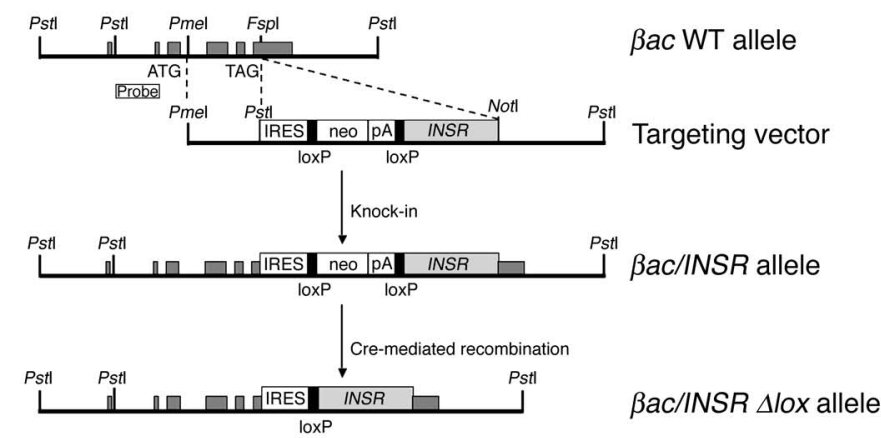

B

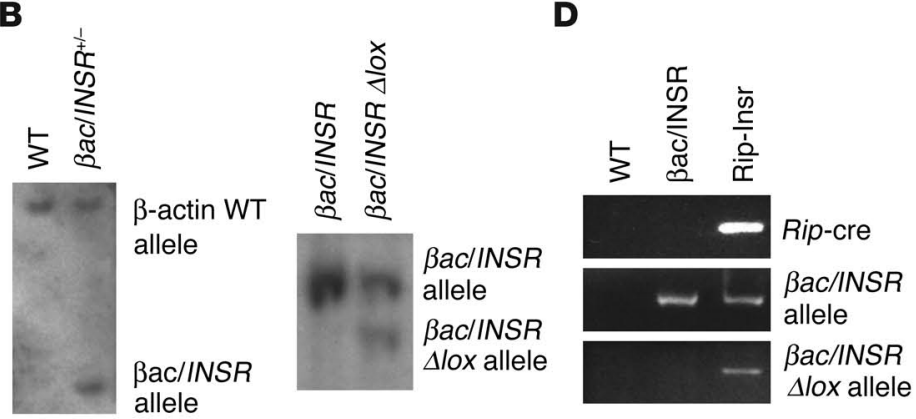

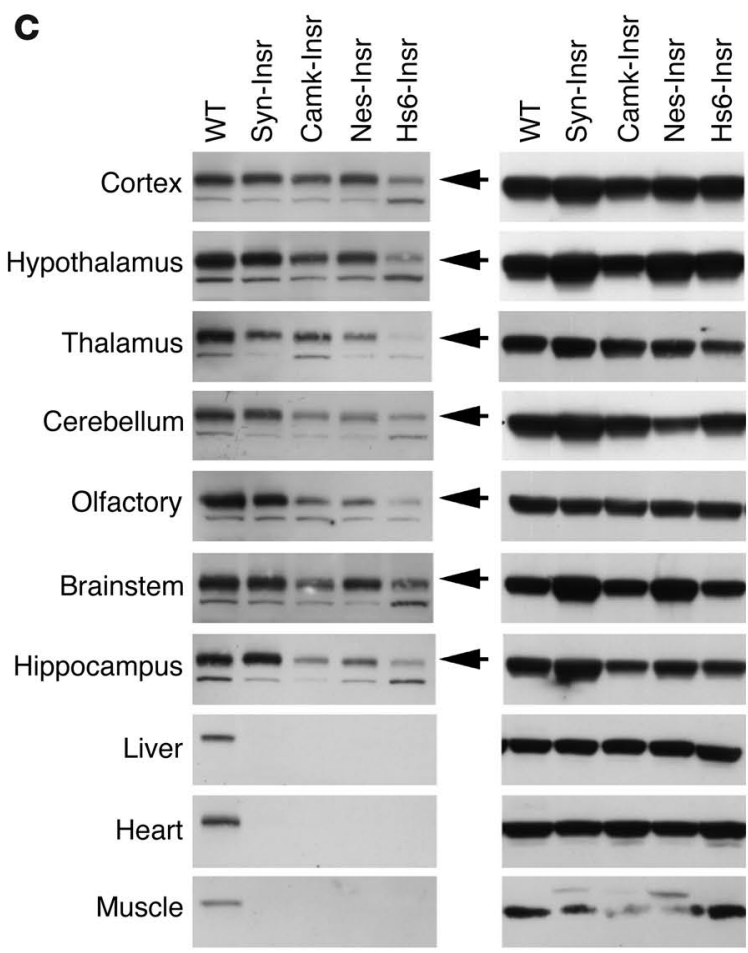

Figure 6

Generation of Insr knock-ins. (A) Targeting vector. Exons are represented by dark gray rectangles. The INSR cDNA was cloned downstream of the TAG stop codon, an internal ribosomal entry site (IRES) and a lox-flanked ("floxed") neomycin-resistance (neo) cassette. (B) Southern blot analysis. DNA was digested with Pstl. Blots were hybridized with an external probe $5^{\prime}$ of the targeted locus. The WT band is about $10 \mathrm{kbp}$ and the recombinant band generated by homologous recombination ( $\beta a c / I N S R$ allele) is about $3 \mathrm{kbp}$. Mice carrying the ac/INSR allele were mated with transgenic mice expressing cre to remove the loxP-neo-lox $P$ cassette. Excision of the neo cassette resulted in the generation of a Bac/INSR $\Delta$ lox allele (right panel, right lane). The upper band corresponds to the intact $\beta a c / I N S R$ allele and the lower band, to the cre-excised Bac/INSR $\Delta$ lox allele. (C) Western blot analysis of Insr (left panel) and tubulin expression (right) in several brain sections, liver, muscle, and heart in Syn-Insr, Camk-Insr, Nes-Insr, and Hs6-Insr mice. (D) Generation of pancreatic $\beta$ cell-specific Insr knock-in. We show PCR analysis of Rip/cre-mediated excision of the $\beta a c / I N S R$ allele in the pancreas. We isolated DNA from pancreata dissected from 2-day-old $\beta a c / I N S R$ Llox/ Insr ${ }^{-1}$ mice and amplified it by PCR with three sets of primers specific for the Rip-cre transgene (upper panel), ßac/INSR allele (middle panel), and $\beta a c / I N S R$ Vlox allele (bottom panel).

could be secondary to diabetes. Interestingly, L1 mice show milder changes in hepatic gene expression than L2 mice do, although the latter express higher transgene levels.

Pancreatic $\beta$ cell compensation in Ttr-Insr mice. We measured pancreatic islet morphology and morphometry as well as islet function in Ttr-Insr-/- mice. At 1 month of age, L1 mice showed islets of normal size with normal architecture (Figure 5A) and a moderate reduction in $\beta$-cell mass (Figure $5 \mathrm{~B}$ ). L2 and L3 mice exhibited increases of about threefold and twofold, respectively, in $\beta$-cell mass (Figure 5, A and B). We also analyzed islet morphology in older animals (4 months old). At this age, L1 mice exhibited normal islet size and architecture, whereas in islets from L2 and L3 mice we found extensive loss of insulin-positive cells, with altered islet architecture (Figure 5C). In contrast, we failed to detect alterations in the expression or subcellular localization of the insulin gene transcription factor Pdx1 (Figure 5C). In vitro assays of glucose-stimulated insulin secretion from purified $\mathrm{L} 1$ islets failed to reveal abnormalities (data not shown). As shown in Figure 3B, islet Insr expression was greater in L2 and L3 than in L1 mice, suggesting that the progressive deterioration of $\beta$-cell function in L2 and L3 mice is secondary to glucotoxicity rather than being a primary defect due to incomplete restoration of Insr expression.
Normal reproductive behavior in L1 but not in L2 and L3 Ttr-Insr mice. We also evaluated the fertility of the three Ttr-Insr ${ }^{-1}$ lines. We set up brother-sister intercrosses and backcrosses with $\mathrm{Insr}^{+/-}$mice (Table 2 ). Both male and female L1 mice were fertile in intercrosses and backcrosses. L2 and L3 male mice produced offspring when backcrossed onto Insr ${ }^{+/-}$female mice, whereas L2 and L3 female mice were sterile. The observation that L1 intercrosses yielded offspring and a normal litter size indicates that Insr signaling in the gonads and reproductive system is not required for germ cell maturation and successful completion of pregnancy. Female L2 and L3 mice could be infertile owing to diabetes. However, because these mice do not express Ins $r$ in the brain, their reproductive phenotype could also be interpreted as supporting the idea of a role for brain Inst in the regulation of gonadotropin production and ovulation (8).

Generation of single-tissue Insr knock-ins in brain and pancreatic $\beta$ cells. The surprising difference in metabolic control between mice expressing Insr in brain, liver, and $\beta$ cells and those with expression limited to liver and $\beta$ cells raised the question of whether restoring insulin action in the brain alone would suffice to prevent diabetes in Insr knockouts. To address this question, we used a conditional locus knock-in approach (24). We modified the $\beta a c$ locus by homologous recombination in ES cells. The modified 
Table 3

Metabolic data in 3-week-old brain-specific Insr knock-in mice

\begin{tabular}{lcccc} 
Genotype & $\begin{array}{c}\text { WT } \\
(\boldsymbol{n}=\mathbf{1 9 )}\end{array}$ & $\begin{array}{c}\text { Syn-Insr } \\
(\boldsymbol{n}=\mathbf{6})\end{array}$ & $\begin{array}{c}\text { Camk-Insr } \\
(\boldsymbol{n}=\mathbf{1 0})\end{array}$ & $\begin{array}{c}\text { Hs6-Insr } \\
(\boldsymbol{n}=\mathbf{1 9})\end{array}$ \\
Body weight & $8.9 \pm 0.4$ & $5.8 \pm 0.4^{\mathrm{B}}$ & $4.7 \pm 0.2^{\mathrm{B}}$ & $6.0 \pm 0.2^{\mathrm{B}}$ \\
Glucose & $126 \pm 6$ & $332 \pm 46^{\mathrm{B}}$ & $367 \pm 16^{\mathrm{B}}$ & $353 \pm 13^{\mathrm{B}}$ \\
Insulin & $0.7 \pm 0.2$ & $8.9 \pm 3.4^{\mathrm{A}}$ & $47.6 \pm 22.6$ & $45.5 \pm 4.5^{\mathrm{B}}$ \\
Ketoacidosis & None & $5 / 6$ & $9 / 10$ & $16 / 19$ \\
Liver steatosis & None & $5 / 6$ & $10 / 10$ & $17 / 19$ \\
\hline
\end{tabular}

We measured whole-blood glucose $(\mathrm{mg} / \mathrm{dll})$, serum insulin $(\mathrm{ng} / \mathrm{dl})$, and urinary ketone levels (Ketoacidosis is defined as acetonacetate greater than $9 \mathrm{mg} / \mathrm{dl}$ or acetone greater than $70 \mathrm{mg} / \mathrm{dl}$ ) in fed mice. We scored for liver steatosis by visual inspection. Statistically significant differences are indicated as follows: ${ }^{A} P<0.05,{ }^{B} P<0.01$.

locus contained an internal ribosome entry site (IRES) at the $3^{\prime}$ end of exon 6, followed by a promoterless lox-neo-lox cassette and by the INSR cDNA (Figure 6, A and B, and Methods). We generated mice heterozygous for the modified $\beta$ ac locus, referred to as $\beta a c / I N S R$ in Figure 6. By breeding these mice with transgenic mice expressing cre recombinase under the control of a tissuespecific promoter, we ensured excision of the lox-neo-lox cassette in a tissue-specific fashion and juxtaposition of the INSR cDNA with IRES. Thus, cre-mediated recombination enables transcription of a bicistronic $\beta a c / I N S R$ mRNA from the IRES (these mice are referred to as $\beta a c / I N S R \Delta l o x$ in Figure 6). We then intercrossed the resulting mice with Insr ${ }^{+/}$mice to introduce a null mutation of the endogenous Insr. By intercrossing the resulting $\mathrm{F}_{1}$ progeny, we obtained $\beta a c / I N S R \Delta l o x$ mice lacking the endogenous Insr (referred to here as $\beta a c / I N S R / \Delta l o x / I n s r^{-/}$mice). We generated four different brain-restricted knock-ins to reactivate Insr expression selectively in neurons using synapsin-cre (25) and calmodulin kinase II-cre (26) transgenic mice, or more broadly in neurons and glia using nestin-cre (Nes-cre) (27) and heat shock protein 70cre (Hs6-cre) (28) transgenic mice. In all instances, we observed the expected pattern of expression of the Inst cDNA in different brain sections, without expression outside the brain (Figure 6C). In all four lines, Insr expression was restored to physiological or near-physiological levels. We observed the highest expression in Syn-Insr mice and the lowest, in Hs6-Insr mice (for nomenclature, see Methods). The metabolic phenotype was similar in all four lines (Table 3). Mice were born in normal mendelian ratios and showed no apparent abnormalities or growth defects but developed diabetes within a week of birth and by 3 weeks of age were frankly diabetic. Most animals died within 6-8 weeks of birth, although few survived up to 3 months. Insulin levels were extremely elevated, indicative of insulin resistance. Mice bearing the intact $\beta a c / I N S R$ allele on an Inst/- background died of diabetic ketoacidosis within few days of birth, similar to Insr ${ }^{-1}$ mice. These findings provide a necessary negative control indicating that the $\beta a c / I N S R$ allele does not allow for INSR expression in the absence of cre. While in principle it would be desirable to recreate the liver/brain pattern of expression using this approach to confirm the transgenic data, we have thus far been unable to obtain robust prenatal expression of Insr in liver using the available transgenic cre lines.

Finally, to address the contribution of Insr in the pancreatic $\beta$ cell to the observed phenotype, we used the modified the $\beta a c / I N S R$ allele to generate mice with $\beta$ cell-restricted Insr expression via intercrosses with rat insulin II promoter-cre (Rip-cre) transgenic mice (29) (Figure 6D). The phenotype of these mice was identical to that of Inst/- mice, suggesting that insulin signaling in the $\beta$ cell is not sufficient to restore even partial metabolic control.

\section{Discussion}

In this study, we demonstrate that Insr expression in liver and pancreatic $\beta$ cells is sufficient to rescue Insr-deficient mice from perinatal lethality but that concomitant expression of Insr in brain is required to prevent diabetes throughout life. The marked effect that restoration of hepatic Insr expression has on the survival of Insr-deficient mice can be accounted for by the dominant role of the liver during lactation in rodents (13). However, the effect of brain Insr in protecting L1 mice from diabetes provides a compelling demonstration of the role of insulin action in the brain (30). Interestingly, L1 mice are resistant to diabetes despite the fact that of the three Ttr-Insr lines characterized, they displayed the lowest levels of transgene expression in both liver and $\beta$ cells. This observation makes it unlikely that the phenotypic differences among the three transgenic lines can be ascribed to their hepatic insulin signaling or $\beta$-cell compensatory ability. Indeed, measurements of insulin-induced Akt activity in livers of L1 mice revealed no differences compared with those of WT mice (data not shown).

Brain and insulin sensitivity. Three studies have addressed the role of Insr in the brain by gene inactivation. Conditional ablation of Insr in nestin-positive neurons results in obesity and decreased female fertility (8), while inhibition of hypothalamic Insr function results in insulin resistance and impaired inhibition of hepatic glucose output $(31,32)$. Our data in brain-restricted Insr knockins indicate that the effect of the brain requires an insulin-sensitive liver to reverse the main abnormalities of the metabolic syndrome. This is consistent with the brain's role in modulating hepatic glucose homeostasis (32). Brain control of insulin action could be exerted in a cell-autonomous fashion, for example through release of endocrine mediators to activate insulin-independent pathways of fuel metabolism (33), or could be due to local release of neuromediators through peripheral nerve endings (34). Intriguingly, the longevity (daner) phenotype caused by mutations in the Insr ortholog daf-2 in Caenorbabditis elegans can be rescued by selective daf-2 re-expression in the brain (35). Moreover, regulation of lifespan in the roundworm has been shown to depend on neural and reproductive inputs (36).

Another intriguing feature of the brain-liver interaction is the reversal of the lipoatrophic phenotype of L2 and L3 mice when Insr expression is reconstituted in the brains of L1 mice. It bears emphasizing that none of the three lines expresses Insr in the adipocyte, indicating that the trophic effect of the brain on adipocytes is cell autonomous, as far as insulin signaling is concerned. Although it may prove difficult to demonstrate whether this effect is due to increased differentiation of pre-adipocytes or decreased lipolysis in existing adipocytes, the findings nevertheless lend support to the idea that the effects of insulin in the central nervous system have profound consequences for peripheral metabolism.

The metabolic balance of power. Conditional mutagenesis using the cre/loxP system provides a new approach for understanding the integrated physiology of insulin action. Classically, insulin resistance has been thought to arise from an impairment of 
insulin-dependent glucose uptake and glycogen synthesis in skeletal muscle and adipose tissue. However, the onset of clinical diabetes requires an increase in hepatic glucose output, with attendant pancreatic $\beta$-cell failure. This has led to the view that two separate defects, one in insulin action and one in pancreatic $\beta$ cell function, are required for the development of type 2 diabetes. Results obtained using mice with targeted mutations in genes required for insulin action have increasingly challenged this view. For example, the demonstration that ablations of Insr (11) and $\operatorname{Igf1r}(21,37)$, as well as their main substrates Irs1 (38) and Irs2 (39), impair $\beta$-cell function has suggested that insulin signaling also plays a role in insulin secretion and in $\beta$ cell compensation to insulin resistance (40). On the other hand, the lack of diabetes or insulin resistance in mice lacking Insr in tissues that possess insulin-dependent mechanisms of glucose uptake has raised the possibility that the contribution of this pathway to the pathogenesis of type 2 diabetes has been overstated (41). The present data provide the firmest evidence to date that insulin signaling in noncanonical insulin target tissues (brain and $\beta$ cells) as well as liver, an organ at the "crossroads" of direct and indirect mechanisms of insulin action (42), is indeed essential for the maintenance of euglycemia.

The results of our study should not be "over-interpreted" to indicate that muscle and fat are unimportant in insulin signaling. The absence of diabetes in Insr-transgenic knockout mice can be explained by the presence of compensatory pathways based on muscle contraction (43) and IGF1 receptor signaling (44). Indeed, inactivation of the insulin-responsive glucose transporter Glut4 in muscle (45) or fat (46) has a more profound effect than Insr inactivation $(6,9)$, suggesting that multiple pathways converge to promote glucose uptake. Likewise, the mechanism by which insulin regulates hepatic glucose production remains unclear (42) and appears to require both direct effects on the hepatocyte as well as indirect effects, mainly through the brain (32). Further metabolic studies of L1 mice will allow us to draw a more definitive conclusion as to which effects predominate in mice. In summary, mice with tissue-restricted Insr expression provide insight into the relative contributions of individual organs to the pathophysiology of insulin resistance, and suggest that therapeutic alternatives based on preserving insulin sensitivity in the brain should be pursued.

\section{Methods}

Animal production and genotyping. The Ttr-Insr transgene was engineered by introduction of a 4.3-kb DNA XbaI-SpeI fragment encoding INSR cDNA at the StuI site of the Ttr exon 3 plasmid, containing $3 \mathrm{kbp}$ of the human Ttr promoter and exons 1-3. This promoter fragment has been shown to confer expression in hepatocytes and pancreatic $\beta$ cells. When the promoter is of high copy number (more than 6 copies), expression in the brain and retinal pigment epithelium has also been demonstrated (17). This purified DNA fragment was microinjected into fertilized C57BL $/ 6 \times$ FVB eggs as described (17). Three founder transgenic mice expressing the Ttr-Insr cDNA were intercrossed with Ins $r^{+/-}$mice and the resulting progeny were intercrossed to yield Ttr-Insr ${ }^{-1}$ mice. Insr ${ }^{-1}$ mice have been described previously (4). The animals were maintained on a mixed background derived from $129 / \mathrm{Sv}$, C57BL/6, and FVB. Genotyping was performed as follows. The WT Ins $r$ allele was detected using primers $5^{\prime}$ CTGTGCACTTCCCTGCTCACA-3' and $5^{\prime}$-TCTTTGCCTGT-
GCTCCACTCT-3'; and the null Insr allele was detected using primers 5'-GATCGGCCATTGAACAAGATG-3' and 5'-CGCCAAGCTCTTCAGCAATAT ${ }^{\prime}{ }^{\prime}$. The product of the WT allele is approximately $300 \mathrm{bp}$ in length and that of the null allele is approximately $700 \mathrm{bp}$ in length. PCR amplification conditions for the WT Insr allele were as follows: 4 minutes at $94^{\circ} \mathrm{C}$, followed by 30 cycles at $94^{\circ} \mathrm{C}$ for 1 minute, $60^{\circ} \mathrm{C}$ for 1 minute, and $72^{\circ} \mathrm{C}$ for 1 minute, and then $72^{\circ} \mathrm{C}$ for 7 minutes. We used similar conditions for the null Insr allele, except that the annealing temperature was $56^{\circ} \mathrm{C}$ and the final extension was for 15 minutes. We detected the transgene using primers $5^{\prime}$-TACCCCGGAGAGGTGTGTCCC- $3^{\prime}$ and $5^{\prime}$-ATGGTCGGGCAAACTTCCTGGCAG$3^{\prime}$. PCR amplification conditions were 4 minutes at $94^{\circ} \mathrm{C}$ followed by 30 cycles at $94^{\circ} \mathrm{C}$ for 1 minute, $65^{\circ} \mathrm{C}$ for 1 minute, and $72^{\circ} \mathrm{C}$ for 1 minute, and then $72^{\circ} \mathrm{C}$ for 7 minutes. The product was approximately $500 \mathrm{bp}$ in length.

Targeted mutagenesis in ES cells and generation of $\beta$ ac/INSR knockin mice. We cloned an INSR cDNA (isoform B) in a modified $\beta$ ac genomic fragment encompassing exons 4-6 of the $\beta$ ac locus (24). The targeting vector was linearized with PmeI and was electroporated into R1 ES cells. After G418 selection, we isolated genomic DNA from individual clones and analyzed them by Southern blotting to detect homologous recombinants by Pst I digestion. Mice carrying the modified $\beta$ ac locus ( $\beta a c / I N S R$ ) were generated by blastocyst injection as described previously (4). To obtain mice with tissue-restricted Insr expression, we bred $\beta a c / I N S R$ mice with Insr ${ }^{+/-}$mice to obtain $\beta a c / I N S R / I n s r^{+/-}$ mice. Similarly, we obtained Insr ${ }^{+/-}$mice carrying the various cre transgenes: synapsin-cre (Syn-cretg/Insr $\left.{ }^{+/}\right)$, calmodulin kinase II-cre (Camk-cretg/Insr $\left.r^{+-}\right)$, nestin-cre (Nes-crets/Insr $\left.{ }^{+-}\right)$, heat shock protein 70-cre (Hs6-crets/Insr ${ }^{+/-}$), and rat insulin II promoter-cre (Rip-crets/ Ins $\left.r^{+-}\right)$. After cre-mediated recombination, the $\beta a c / I N S R$ allele is expected to undergo deletion of the lox-neo-lox cassette, thus yielding a $\beta a c / I N S R \Delta$ lox allele. Intercrosses between the doubleheterozygous $\beta a c / I N S R / I n s r^{+/-}$mice and $\mathrm{cre}^{t g} / \mathrm{Insr}^{+/-}$mice yielded mice of the following genotypes, used for further analyses: WT, $\beta a c / I N S R / I_{n s r^{--}}$, and $\beta a c / I N S R \Delta$ lox/Insr ${ }^{-/}$. For simplicity, these last five types of mice are referred to as Syn-Insr, Camk-Insr, Nes-Insr, Hs6-Insr, and Rip-Insr, respectively.

Hybridization studies. We performed Southern analysis on Hin$d$ III-digested DNA obtained from tail tissue using a cloned fragment of the INSR cDNA (nucleotides 2,091-3,068) as a ${ }^{32} \mathrm{P}$ labeled hybridization probe. We isolated total RNA from liver using TRIzol (Life Technologies, Gaithersburg, Maryland, USA). We size-fractionated isolated samples on a denaturing formaldehyde/agarose gel and transferred them to a nylon membrane for Northern hybridization according to standard techniques, using the same probe described for Southern analysis. The probe detects human INSR but not mouse Insr mRNA.

$R T-P C R$ and real-time RT-PCR analysis. We isolated mRNA using the Micro-FastTrack 2.0 Kit (Invitrogen, Carlsbad, California, USA) and used this mRNA to synthesize cDNA using a GeneAmp RNA PCR kit (Perkin-Elmer, Boston, Massachusetts, USA). We isolated total RNA using TRIzol (Life Technologies). We performed PCR using cDNA as a template and an amplification primer set (forward, 5'-GGCTGAAGCTGCCCTCGA-3'; reverse, 5' -CACGCTGGTCGAGGAAGT-3') that specifically detects human INSR but not mouse Ins $r$ cDNA. PCR amplification conditions were 2 minutes at $95^{\circ} \mathrm{C}$, followed by 35 cycles at $95^{\circ} \mathrm{C}$ for 1 minute, $60^{\circ} \mathrm{C}$ for $1 \mathrm{~min}$ ute, and $72^{\circ} \mathrm{C}$ for 1 minute, with a final cycle at $72^{\circ} \mathrm{C}$ for 7 minutes. 
We carried out real-time PCR in duplicate with SYBR Green using a LightCycler instrument (Roche Molecular Biochemicals, Indianapolis, Indiana, USA). To normalize RNA content we used amplification of $\beta a c$ mRNA. We used the following primer sets to amplify the various mRNAs: Insr, $5^{\prime}$-GGCTGAAGCTGCCCTCGA $3^{\prime}$ and $5^{\prime}$ GCTGCCACCGTGGGCACGGCCA 3'; $\beta a c, 5^{\prime}$-CTAGAAGCACTTGCGGTGCAC-3' and $5^{\prime}$-GAAATCGTGCGTGACATCAAA-3'; G6pc, 5'-GCTTGGATTCTACCTGCTAC-3' and 5'-AAAGACTTCTTGTGTGTCTGTC-3'; Pck1, 5'-CCACAGCTGCTGCAGAACA-3' and $5^{\prime}$-AAAGACTTCTTGTGTGTCTGTC-3'; Gs, 5'-GGGGAAGACAGTGAGCGTTATG-3' and ${ }^{\prime}$ '-TCAAGAGTCTGGAGTGGGGTTCAG-3'; and Igfbp1, $5^{\prime}$-AGATCGCCGACCTCAAGAAAT$3^{\prime}$ and $5^{\prime}$-CTCCAGAGACCCAGGATTTT-3'.

Protein expression studies. We prepared detergent extracts from liver, brain, muscle, heart, spleen, pancreatic islets, and epididymal fat pads in buffer containing $50 \mathrm{mM}$ HEPES, 9.6\% glycerol, $1 \%$ Triton $\mathrm{X}-100,150 \mathrm{mM}$ sodium chloride, $1.5 \mathrm{mM}$ magnesium chloride, 2.5 mM EDTA (pH 8.0), 1 mM DTT, and 2 mM PMSF. We resolved equal amounts of protein $(1.05 \mathrm{mg}$ for liver, 0.3 $\mathrm{mg}$ for brain, $0.9 \mathrm{mg}$ for muscle, $0.6 \mathrm{mg}$ for heart, $0.75 \mathrm{mg}$ for spleen, $0.075 \mathrm{mg}$ for pancreatic islets, and $0.012 \mathrm{mg}$ for fat) by $8 \%$ SDS-PAGE and transferred them to nitrocellulose membrane (Protoran; Schleicher \& Schuell, Keene, New Hampshire, USA). We probed the filters with anti-Insr $\beta$ subunit (C-19; Santa Cruz Biotechnologies, Santa Cruz, California, USA) at a dilution of 1:1,000. We detected bound antibody with horseradish peroxidase-coupled antibody against rabbit IgG (Amersham Pharmacia Biotech, Little Chalfont, Buckinghamshire, United Kingdom) at a dilution of 1:5,000 using the ECL detection system (Amersham Pharmacia Biotech).

Metabolic analyses. The Columbia University Institutional Animal Care and Utilization Committee have approved all procedures. We have described in previous publications bleeding and metabolic testing procedures, as well as insulin RIAs (Linco, St. Charles, Missouri, USA) (22).

Glycogen content assays. We dissolved about $80 \mathrm{mg}$ of liver samples in $\mathrm{NaOH}$ and incubated this at $65^{\circ} \mathrm{C}$ for 2 hours. We precipitated glycogen in ethanol and performed limited digestion with amylo- glucosidase (Sigma-Aldrich, St. Louis, Missouri, USA). We determined glucose using the Trinder glucose assay kit (Sigma-Aldrich). We performed all determinations in duplicate and expressed the results as means \pm SEM (mg glycogen $/ g$ protein).

Immunohistochemical analysis of pancreatic islets. We fixed pancreata overnight in Bouin's solution, embedded the specimens in paraffin, and mounted consecutive sections $5 \mu \mathrm{m}$ in thickness on slides (47). We stained sections with anti-insulin, anti-glucagon (Sigma-Aldrich) and anti-Pdx1 (a kind gift from C. Wright, Vanderbilt University, Nashville, Tennessee, USA). We detected antiserum using rhodamine- and fluorescein-conjugated secondary antibodies (Jackson ImmunoResearch Laboratories, West Grove, Pennsylvania, USA) (22). We measured $\alpha$ - and $\beta$ cell mass as described (21) using three sections per pancreas and four mice for each genotype.

Insulin secretion from isolated islets. We isolated pancreatic islets by collagenase digestion followed by centrifugation over a Histopaque gradient (Sigma-Aldrich) and performed insulin secretion assays as described previously (47).

Statistical analyses. We calculated descriptive statistics and ANOVA followed by Fisher's test using StatView software (Abacus Concepts, Berkeley, California, USA).

\section{Acknowledgments}

This work was supported by grants from the NIH (DK58282 and DK57539), by the Columbia Diabetes and Endocrinology Research Center (DK63608), and by a Juvenile Diabetes Research Foundation fellowship to T. Kitamura. We thank Y. Liu for skillful assistance with immunohistochemistry, and members of the Accili laboratory for helpful discussions.

Received for publication March 18, 2004, and accepted in revised form May 28, 2004.

Address correspondence to: Domenico Accili, Berrie Research Pavilion,1150 St. Nicholas Avenue, Room 238A, New York, New York 10032, USA. Phone: (212) 851-5332; Fax: (212) 851-5331; E-mail: da230@columbia.edu.
1. Saltiel, A.R., and Kahn, C.R. 2001. Insulin signalling and the regulation of glucose and lipid metabolism. Nature. 414:799-806.

2. Fujimoto, W.Y. 2000. The importance of insulin resistance in the pathogenesis of type 2 diabetes mellitus. Am. J. Med. 108:9S-14S.

3. Kitamura, T., Kahn, C.R., and Accili, D. 2003 Insulin receptor knockout mice. Annu. Rev. Physiol. 65:313-332.

4. Accili, D., et al. 1996. Early neonatal death in mice homozygous for a null allele of the insulin receptor gene. Nat. Genet. 12:106-109.

5. Joshi, R.L., et al. 1996. Targeted disruption of the insulin receptor gene in the mouse results in neonatal lethality. EMBO J. 15:1542-1547.

6. Bruning, J.C., et al. 1998. A muscle-specific insulin receptor knockout exhibits features of the metabolic syndrome of NIDDM without altering glucose tolerance. Mol. Cell. 2:559-569.

7. Michael, M.D., et al. 2000. Loss of insulin signaling in hepatocytes leads to severe insulin resistance and progressive hepatic dysfunction. Mol. Cell. 6:87-97.

8. Bruning, J.C., et al. 2000. Role of brain insulin receptor in control of body weight and reproduction. Science. 289:2122-2155.

9. Bluher, M., et al. 2002. Adipose tissue selective insulin receptor knockout protects against obesity and obesity-related glucose intolerance. Dev. Cell. 3:25-38.

10. Kim, J.K., et al. 2000. Redistribution of substrates to adipose tissue promotes obesity in mice with selective insulin resistance in muscle. J. Clin. Invest. 105:1791-1797.

11. Kulkarni, R.N., et al. 1999. Tissue-specific knockout of the insulin receptor in pancreatic beta cells creates an insulin secretory defect similar to that in type 2 diabetes. Cell. 96:329-339.

12. Lauro, D., et al. 1998. Impaired glucose tolerance in mice with a targeted impairment of insulin action in muscle and adipose tissue. Nat. Genet. 20:294-298.

13. Girard, J., Ferre, P., Pegorier, J.P., and Duee, P.H. 1992. Adaptations of glucose and fatty acid metabolism during perinatal period and suckling-weaning transition. Physiol. Rev. 72:507-562.

14. Allen-Jennings, A.E., Hartman, M.G., Kociba, G.J., and Hai, T. 2001. The roles of atf3 in glucose homeostasis. a transgenic mouse model with liver dysfunction and defects in endocrine pancreas. J. Biol. Chem. 276:29507-29514.

15. Rausa, F.M., et al. 2000. Elevated levels of hepatocyte nuclear factor 3 beta in mouse hepatocytes influence expression of genes involved in bile acid and glucose homeostasis. Mol. Cell Biol. 20:8264-8282.

16. Lai, E., et al. 1990. HNF-3A, a hepatocyte-enriched transcription factor of novel structure is regulated transcriptionally. Genes Dev. 4:1427-1436.

17. Nakae, J., et al. 2002. Regulation of insulin action and pancreatic beta-cell function by mutated alleles of the gene encoding forkhead transcription factor Foxo1. Nat. Genet. 32:245-253.

18. Yan, C., Costa, R.H., Darnell, J.E., Jr., Chen, J.D., and Van Dyke, T.A. 1990. Distinct positive and negative elements control the limited hepatocyte and choroid plexus expression of transthyretin in transgenic mice. EMBO J. 9:869-878.

19. Zhou, H., et al. 2001. Atypical mouse cerebellar development is caused by ectopic expression of the forkhead box transcription factor HNF-3beta. Gene Expr. 9:217-236.

20. Hirayama, I., et al. 1999. Insulin receptor-related receptor is expressed in pancreatic beta-cells and stimulates tyrosine phosphorylation of insulin receptor substrate-1 and -2. Diabetes. 48:1237-1244.

21. Xuan, S., et al. 2002. Defective insulin secretion in pancreatic beta cells lacking type 1 IGF receptor. J. Clin. Invest. 110:1011-1019. doi:10.1172/ JCI200215276.

22. Kido, Y., et al. 2000. Tissue-specific insulin resistance in mice with mutations in the insulin receptor, IRS-1, and IRS-2. J. Clin. Invest. 105:199-205.

23. Kido, Y., Philippe, N., Schaffer, A.A., and Accili, D. 
2000. Genetic modifiers of the insulin resistance phenotype in mice. Diabetes. 49:589-596.

24. Politi, K., et al. 2004. 'Designer' tumors in mice. Oncogene. 23:1558-1565.

25. Zhu, Y., et al. 2001. Ablation of NF1 function in neurons induces abnormal development of cerebral cortex and reactive gliosis in the brain. Genes Dev. 15:859-876.

26. Dragatsis, I., and Zeitlin, S. 2000. CaMKIIalpha-Cre transgene expression and recombination patterns in the mouse brain. Genesis. 26:133-135.

27. Tronche, F., et al. 1999. Disruption of the glucocorticoid receptor gene in the nervous system results in reduced anxiety. Nat. Genet. 23:99-103.

28. Dietrich, P., Dragatsis, I., Xuan, S., Zeitlin, S., and Efstratiadis, A. 2000. Conditional mutagenesis in mice with heat shock promoter-driven cre transgenes. Mamm. Genome. 11:196-205.

29. Herrera, P.L. 2000. Adult insulin- and glucagonproducing cells differentiate from two independent cell lineages. Development. 127:2317-2322.

30. Porte, D., Jr., Baskin, D.G., and Schwartz, M.W. 2002. Leptin and insulin action in the central nervous system [review]. Nutr. Rev. 60:S20-S29.

31. Obici, S., Feng, Z., Karkanias, G., Baskin, D.G., and Rossetti, L. 2002. Decreasing hypothalamic insulin receptors causes hyperphagia and insulin resistance in rats. Nat. Neurosci. 5:566-572.

32. Obici, S., Zhang, B.B., Karkanias, G., and Rossetti, L. 2002. Hypothalamic insulin signaling is required for inhibition of glucose production. Nat. Med. 8:1376-1382

33. Schwartz, M.W., Woods, S.C., Porte, D., Jr., Seeley, R.J., and Baskin, D.G. 2000. Central nervous system control of food intake. Nature. 404:661-671.

34. Cherrington, A.D. 1999. Banting Lecture 1997. Control of glucose uptake and release by the liver in vivo. Diabetes. 48:1198-1214.

35. Wolkow, C.A., Kimura, K.D., Lee, M.S., and Ruvkun, G. 2000. Regulation of C. elegans life-span by insulinlike signaling in the nervous system. Science. 290:147-150.

36. Apfeld, J., and Kenyon, C. 1998. Cell nonautonomy of C. elegans daf- 2 function in the regulation of diapause and life span. Cell. 95:199-210.

37. Kulkarni, R.N., et al. 2002. Beta-cell-specific deletion of the Igf1 receptor leads to hyperinsulinemia and glucose intolerance but does not alter beta-cell mass. Nat. Genet. 31:111-115.

38. Kulkarni, R.N., et al. 1999. Altered function of insulin receptor substrate-1-deficient mouse islets and cultured beta-cell lines. J. Clin. Invest. 104:69-75.

39. Withers, D.J., et al. 1998. Disruption of IRS-2 causes type 2 diabetes in mice. Nature. 391:900-904.
40. Accili, D. 2001. A kinase in the life of the beta cell. J. Clin. Invest. 108:1575-1576. doi:10.1172/ JCI200114454.

41. Hribal, M.L., Oriente, F., and Accili, D. 2002. Mouse models of insulin resistance. Am. J. Physiol. Endocrinol. Metab. 282:E977-E981.

42. Barrett, E.J. 2003. Insulin's effect on glucose production: direct or indirect? J. Clin. Invest. 111:434-435. doi:10.1172/JCI200317881.

43. Wojtaszewski, J.F., et al. 1999. Exercise modulates postreceptor insulin signaling and glucose transport in muscle-specific insulin receptor knockout mice. J. Clin. Invest. 104:1257-1264.

44. Fernandez, A., et al. 2001. Functional inactivation of the IGF-I and insulin receptors in skeletal muscle causes type 2 diabetes. Genes Dev. 15:1926-1934.

45. Zisman, A., et al. 2000. Targeted disruption of the glucose transporter 4 selectively in muscle causes insulin resistance and glucose intolerance. Nat. Med. 6:924-928.

46. Abel, E.D., et al. 2001. Adipose-selective targeting of the GLUT4 gene impairs insulin action in muscle and liver. Nature. 409:729-733.

47. Kitamura, T., et al. 2001. Preserved pancreatic betacell development and function in mice lacking the insulin receptor-related receptor. Mol. Cell Biol. 21:5624-5630. 